www.cya.unam.mx/index.php/cya

Contaduría y Administración, 65 (4), Especial COVID-19, 2020, 1-19

\title{
Nuevos mecanismos de colaboración público-privada para el desarrollo y acceso a la vacuna COVID-19: una perspectiva desde la teoría fundamentada
}

\section{New public-private collaboration mechanisms for the development and access to the COVID-19 vaccine: A perspective from grounded theory}

\author{
Javier Jasso-Villazul $^{1 *}$, Arturo Torres-Vargas ${ }^{2}$ \\ ${ }^{1}$ Universidad Nacional Autónoma de Mexico, México \\ ${ }^{2}$ Universidad Autónoma Metropolitana, México \\ Recibido el 30 de octubre de 2020; aceptado el 27 de noviembre de 2020 \\ Disponible en Internet el: 30 de noviembre de 2020
}

\section{Resumen}

El objetivo de este texto es identificar y caracterizar cómo ante un hecho global de alto impacto, como puede ser una pandemia, se crean nuevas formas de colaboración y competencia entre los agentes (empresas, centros públicos de investigación y universidades, gobiernos), para acelerar el desarrollo de la vacuna para mitigar la pandemia de la enfermedad por coronavirus 2019 (COVID-19). El texto analiza el proceso de producción de vacunas para enfrentar al coronavirus SARS-CoV-2 a partir de las candidatas que se encuentran en la etapa de estudios clínicos de las fases más avanzadas, considerando las características de los agentes, los países a los que pertenecen, el perfil del financiamiento y los rasgos de la regulación. La aportación del trabajo es la de señalar que en el desarrollo de la vacuna de la COVID-19 se han impulsado nuevos patrones de colaboración público-privado a nivel nacional e internacional en múltiples ámbitos como son el científico-tecnológico, el financiero y el regulatorio. Estos patrones enmarcan una nueva lógica de colaboración que pudiera ser una experiencia para resolver problemas globales como son las pandemias, con una mayor flexibilidad y velocidad.

Código JEL: F50, I 15, L65, O10, O30

Palabras clave: Vacuna COVID-19; Colaboración público -privada; Coronavirus; Desarrollo y acceso de la vacuna COVID-19; Teoría fundamentada

\footnotetext{
* Autor para correspondencia

Correo electrónico unamdicai@ gmail.com (J. Jasso Villazul).

La revisión por pares es responsabilidad de la Universidad Nacional Autónoma de México.

http://dx.doi.org/10.22201/fca.24488410e.2020.3134

0186- 1042/@ 2019 Universidad Nacional Autónoma de México, Facultad de Contaduría y Administración. Este es un artículo Open Access bajo la licencia CC BY-NC-SA (https://creativecommons.org/licenses/by-nc-sa/4.0/)
} 


\begin{abstract}
The aim of this work is to identify and characterize how in the facing of a global event of high-impact, such as a pandemic, new forms of collaboration and competition among agents (companies, public research centers and universities, governments) emerge to accelerate the development of the vaccine to mitigate the pandemic of coronavirus disease 2019 (COVID-19). The text analyses the vaccine production process to face the SARS-CoV-2 coronavirus from the vaccine candidates that are in the stage of clinical studies of the most advanced phases by considering the characteristics of the agents, the countries to which they belong, the financing profile and the regulation features. The contribution of the work is to point out that in the development of the COVID-19 vaccine, new patterns of public-private collaboration have been promoted at the national and international level in multiple areas such as the scientific-technological, financial and regulatory. These patterns frame a new collaboration logic that could be an experience to solve global problems such as pandemics, with greater flexibility and speed.
\end{abstract}

JEL code: F50, I 15, L65, O10, O30

Keywords: COVID-19 vaccine; Public-private collaboration; Coronavirus; Vaccine development and access; Grounded Theory

\title{
Introducción
}

A partir del surgimiento de un nuevo virus de la familia coronavirus identificado en China en noviembre del 2019 se ha generado una pandemia de la enfermedad denominada COVID-19. Los niveles de contagio han alcanzado a prácticamente todos los países, con tasas de morbilidad y mortalidad que han generado la voz de alerta para hacer frente a un nuevo problema global de salud pública. En los años recientes la humanidad se ha visto afectada por enfermedades asociadas con la circulación de nuevos y viejos serotipos y prototipos de virus. Esto es, existen virus emergentes que aparecen en sitios donde nunca se habían diagnosticado, o bien, virus reemergentes que aparecen donde ya habían sido controlados. Entre los factores que favorecen esta circulación se encuentra la masificación de las ciudades, la deforestación y la invasión de áreas ecológicas silvestres o despobladas. Por otra parte, la mayor movilidad de personas, animales y de mercancías, está expandiendo con mayor celeridad que nunca los agentes infecciosos. Las últimas amenazas virales del periodo reciente derivan de cepas como la aviar H5N1, o los virus ébola, marburg, lassa y otros causantes de fiebres hemorrágicas virales contagiosas. Las familias de los coronavirus en los humanos se encuentran desde al menos hace ocho siglos (HCoVNL63) hasta llegar a los más recientes de los tipos SARS-CoV-1 y 2 y MERS-CoV apenas identificados en el presente siglo. No es posible saber cuántos virus capaces de infectar al ser humano, animales y plantas quedan aún por descubrir, ni cuantos se podrán detectar con las nuevas técnicas de diagnóstico (Reina et al, 2014). La gran agresividad del SARSCoV-2 contrasta con las especies conocidas de esta familia. La familia de virus SARS se caracteriza por su capacidad de mutabilidad, lo que dificulta la previsión epidemiológica y el posible desarrollo de una vacuna. La familia coronavirus está muy extendida en el reino animal, y es una de las causas más frecuentes de resfriado en humanos.

Hasta la fecha (21 de noviembre de 2020) no se ha creado un tratamiento confiable que pueda detener de manera predecible la progresión de la enfermedad COVID-19, que la ha caracterizado como una enfermedad que puede ser leve, moderada, grave e incluso potencialmente mortal. Este problema de salud pública global ha planteado la urgencia de desarrollar vacunas contra el virus del SARS-CoV-2, a la que varios países e instituciones como la OMS se han abocado. Las candidatas a vacunas para prevenir la COVID-19 se basan en estrategias para inducir respuestas inmunitarias, incluida la generación de anticuerpos neutralizantes, dirigidos contra la proteína "de pico" spike del SARS-CoV-2. Al considerarse a la pandemia COVID19 como una situación de emergencia global, existe un amplio consenso mundial de que se deben idear formas innovadoras para acelerar el desarrollo de candidatos a vacunas prometedoras y eficaces en el menor tiempo posible (WHO, 2020c). Este trabajo explora los mecanismos complementarios al mercado que han sido generados para acelerar su desarrollo (producción) y acceso (distribución).

Utilizamos una metodología fundamentada. Glaser y Strauss (1967) propusieron la Teoría Fundamentada (TF) (en inglés Grounded Theory) como una manera alternativa de aproximarse a la realidad social. En oposición a las 


\section{J. Jasso-Villazul y A. Torres-Vargas / Contaduría y Administración 65(4) Especial COVID-19, 2020, 1-19 http://dx.doi.org/10.22201/fca.24488410e.2020.3134}

aproximaciones hipotético-deductivas, la TF es una es una aproximación inductiva de la investigación que privilegia el contexto o fenómeno sobre la teoría a partir los datos (Walsh et al, 2015). Así, cambiando el orden usual de la revisión de la literatura y la recolección de los datos, la TF busca adaptar los descubrimientos previos a las características específicas del fenómeno en estudio (Hirschman y Thompson, 1997). Partimos de la pregunta: ¿En qué medida el desarrollo de vacunas ante una pandemia es factible de acelerarse a partir de una mayor coordinación y colaboración público-privado internacional en los ámbitos científico-tecnológico, financiero y regulatorio? Nuestro argumento es que el desarrollo de la vacuna COVID19 y la velocidad para utilizarse está siendo posible debido al conocimiento acumulado por empresas y CPI-universidades, y a las capacidades institucionales y de articulación entre países y agentes que han conformado nuevos esquemas de colaboración público-privado. Esto se refleja en una mayor intensidad en la colaboración científicotecnológica, en la generación de mecanismos de coordinación y financiamiento público y privado para reducir el riesgo en la inversión de la vacuna, así como en la flexibilidad y aceleración de las regulaciones a nivel nacional e internacional. Respecto a las capacidades científico-tecnológicas consideramos que para desarrollar una vacuna se requiere que los países, empresas, CPI y universidades cuenten con capacidades científico-tecnológicas cubriendo el espectro que va desde las actividades de I+D a las de comercialización, así como de personal científico y técnico especializado. Estas capacidades requieren de financiamiento público y privado, y de mecanismos para coordinar e integrar los conocimientos

y habilidades de cada agente desarrollador al interactuar o colaborar con otros agentes públicos y privados que incluyen a las agencias reguladoras, lográndose nuevas o recombinadas capacidades.

Analizamos los proyectos de vacuna COVID-19 identificados por la Organización Mundial de la Salud que se encontraban en las etapas más avanzadas (estudios clínicos fases 1, 2, 1-2 y 3) hasta el día 15 de octubre de 2020. En el análisis de las candidatas a vacuna se consideran sus características como son la plataforma tecnológica empleada, el número de vacunas, el grado de avance, el tipo e intensidad de la vinculación entre los diversos agentes, rasgos del agente ya sea para compartir conocimiento o recibir financiamiento, el tipo de financiamiento público o privado, la nacionalidad del agente y la naturaleza de la vinculación. A partir del análisis de los datos, conceptos y de una amplia información documental identificamos diversos patrones de comportamiento del desarrollo y acceso a la vacuna COVID-19, siguiendo el esquema de la TF (Walsh et al, 2015).

El texto consta de seis apartados. En el primero que es esta introducción en donde se plantea el problema y se describe en general la metodología a utilizar. En el segundo apartado se presenta el marco teórico. En los apartados tercero al quinto, se presentan y discuten los resultados. Finalmente, en el sexto apartado se presentan las conclusiones.

\section{El desarrollo y producción de vacunas: el mercado y la salud pública global}

El desarrollo y la producción de vacunas se realiza en el contexto de una estructura industrial específica, con procesos de innovación de alta complejidad, riesgo y costos, y con esquemas de participación de las empresas, Centros Públicos de Investigación (CPI, incluye hospitales) y universidades que están permeados por el mercado y la regulación, y por ello de la dinámica público-privada.

\section{La innovación y la colaboración científico-tecnológica}

La innovación tiene un carácter colectivo, acumulativo, e incierto. En el caso de las vacunas este proceso es bastante claro. Se trata de un proceso colectivo que involucra un conjunto de actores y de recursos productivos y organizacionales, de la integración de una diversidad de conocimientos, de personas con diferentes formaciones y habilidades, lo cual funciona como una red de agentes, conocimientos e instituciones. El carácter acumulativo se refiere a trayectorias de conocimiento básico y tecnológico sobre los cuales se construyen nuevo conocimiento y soluciones tecnológicas que dan 
origen a mejoras en productos y procesos, o a innovaciones radicales. El conocimiento previo es la base de los avances del conocimiento que se construye hoy. La búsqueda de la vacuna contra el SARS-CoV-2 tiene su fundamento en los avances científicos y tecnológicos acumulados en universidades y centros públicos de investigación, laboratorios y centros de I+D de las empresas y gubernamentales e instituciones y organismos internacionales. En el desarrollo de nuevos descubrimientos, como las vacunas, no hay garantía de que el proceso de investigación va a dar frutos de manera rápida y certera, es decir, la incertidumbre es importante, y alguien debe de asumir el costo. La discusión nos lleva a la reflexión acerca de la participación de diferentes actores para lograr una solución, dados los riesgos y beneficios esperados, ¿quién está dispuesto a invertir?. Se asume que, en situaciones de alto riesgo, y de alto impacto social como el de las vacunas, el Estado debe desempeñar un papel fundamental. Al respecto, Jacobs y Mazzucato (2016) señalan que el Estado debe de desempeñar un rol como "creador de oportunidades", invirtiendo en etapas de más alto riesgo del proceso, y haciendo un papel de formador del mercado, ya sea generando las condiciones para que un sector se desarrolle, o interviniendo en un esquema público-privado de creación de mercados específicos, y no solo participando como actor que corrige sus fallas.

En la industria de vacunas el proceso de descubrimiento y producción comercial ha transitado de "técnicas aleatorias" a "técnicas dirigidas", con lo cual el alto grado de concentración de la producción en un pequeño grupo de grandes empresas multinacionales se ha complementado con la entrada de pequeñas empresas biotecnológicas, a partir de la revolución en este sector iniciada en los años 1980s. Estas empresas biotecnológicas están teniendo un importante rol en las etapas tempranas del proceso de descubrimiento de nuevos medicamentos, mientras que, las firmas grandes se encargan de las etapas de desarrollo, pruebas clínicas, revisión de procesos regulatorios y actividades de mercadeo (Demirel y Mazzucato, 2010). Sin embargo, la estructura de mercado del sector sigue siendo dominada por un pequeño número de grandes empresas multinacionales, que en muchos casos han absorbido a las pequeñas empresas biotecnológicas. Cuatro empresas controlan el 80\% del mismo: Glaxo Smith Kline, Merck Sharp \& Dohme, Sanofi y Pfizer, que sumaron 24,870 millones de dólares en 2017 (Evaluate Pharma, 2017). El capital de riesgo, propio de los mercados financieros, se utilizó en la biotecnología, una vez que el Estado había financiado las etapas de mayor riesgo y de mayor intensidad de capital en el desarrollo de esta tecnología, lo que ocurrió a los 20 años. En la actualidad, la biotecnología de la salud es uno de los sectores más apoyados por el Estado en países como EUA, China, Alemania y Dinamarca.

\section{El Estado y los mecanismos de coordinación y financiamiento público-privado en la salud pública}

Existe una discusión en torno a la participación de estos actores, sus objetivos y los intereses que se pueden manifestar en un proceso tan complejo como la salud pública y la ciencia y la tecnología. El Estado ha desempeñado un papel fundamental. Desde la perspectiva de la teoría económica ortodoxa, la participación del Estado se justifica cuando existen fallas en el mercado, esto es, cuando el sistema de precios no es capaz de asignar los recursos de manera eficiente, tal que se logre el abasto de todos los bienes y servicios en una economía. En el ámbito de la salud, un caso es el de la producción y abasto de los llamados medicamentos huérfanos, dirigidos a enfermedades raras y poco frecuentes, que no permiten la recuperación del capital invertido en la investigación requerida para encontrar la molécula activa. Las empresas en general buscan la rentabilidad, entrando al mercado cuando la obtención de retornos es más certera. Es entonces que la inversión pública cubre esas fallas de mercado; las vacunas pueden ser un típico caso debido a los altos costos de I+D que requieren, el componente de incertidumbre que acompaña al proceso de innovación, y alto contenido de complejidad del conocimiento que está en su base. Desde nuestra perspectiva, el Estado puede asumir otros roles. Al respecto, Polanyi (1944) argumentó que el Estado podía considerarse no sólo como un ente existente al lado de los mercados en los que la política pública sólo se dirige a darles forma mediante regulaciones e incentivos. Esto es, que el Estado debe participar profundamente en el proceso de creación de los mercados, ya que éstos están incrustados en las instituciones políticas y 
sociales. Así, el papel del Estado sería, no el de apoyar las acciones que ya se están haciendo, sino el de realizar las que no se están haciendo, por lo que la política pública aparece como creadora de nuevos escenarios (landscapes). En el desarrollo de la vacuna contra la COVID-19 se plantea que se diseñen nuevos esquemas de participación para la cooperación público-privada. La participación del Estado en la ciencia a través de apoyos públicos no se reduce al financiamiento de investigación básica y aplicada, incluye el financiamiento de etapas tempranas de la innovación en empresas, que son consideradas demasiado riesgosas por el sector financiero privado. En los últimos 50 años la participación del Estado emprendedor por medio de apoyos públicos a la ciencia y las nuevas tecnologías como el internet o la nanotecnología ha sido muy importante (Jacobs y Mazzucato, 2016). En la industria farmacéutica en EUA, se estima que el $75 \%$ de los medicamentos más innovadores deben mucho de su financiamiento a los fondos de los Institutos Nacionales de Salud. El desarrollo de la vacuna es el primer eslabón en la cadena de solución del problema pandémico en el que también están el escalamiento, la manufactura, la distribución y la aplicación en la población.

Desde la perspectiva de los estudios de la innovación y de la idea de agentes o actores, la cooperación incluye a las universidades y centros públicos de investigación, los gobiernos y las empresas (Etzkowitz y Leydesdorff, 2000). La industria productora de medicamentos y vacunas tiene una fuerte base en la generación y aplicación de conocimiento, muchas veces producido en los centros públicos de investigación y que vinculados con las empresas farmacéuticas reciben recursos públicos para financiar la I+D. El desarrollo de las vacunas y otras innovaciones de inmunización deben de someterse a procesos regulatorios y de fabricación cada vez más complejos que son guiados por el sector público. La participación del Estado es determinante para la autorización de la vacuna y el posible apoyo público y de otros agentes e instituciones en la manufactura, sistemas de distribución y logística que requieren coordinarse, como es el caso de las vacunas de la COVID-19.

\section{El desarrollo de vacunas COVID-19}

\section{La necesidad de crear una vacuna y sus fases de desarrollo}

A finales de noviembre de 2020 los contagios a nivel mundial eran de poco más de 60 millones de personas y el número de muertos habían superado los 1.5 millones de personas. La velocidad de los contagios y muertes, refleja que la mitigación de la pandemia no se había logrado, lo que se espera ocurra una vez que haya nuevos tratamientos efectivos y sobre todo con el desarrollo de una vacuna (Figura 1).

El proceso para elaborar una vacuna debe aprobar una serie de exigencias regulatorias de cada país que están estandarizadas a nivel internacional y que deben ser sometidas a verificaciones científicas. Las vacunas suelen requerir años de investigación y pruebas antes de llegar al mercado sobre todo para aquellas enfermedades infecciosas que suelen ser menos letales, a menudo infecciones endémicas que no son consideradas de PHEIC [Emergencia de salud pública de interés internacional], y para las que actualmente no existen vacunas autorizadas. Dicho proceso sigue dos etapas de pruebas que inician con los estudios preclínicos que consisten en pruebas en laboratorio y en animales y la etapa de estudios clínicos que son pruebas en seres humanos y que abarcan las fases 1, 2 y 3. Los primeros ensayos de fase 1 en decenas de personas se centran principalmente en la seguridad. Los datos que indican la aceptabilidad clínica y la inmunogenicidad en la fase 1 conducen a ensayos de fase 2, que a menudo comparan varios programas de inmunización diferentes o diferentes formulaciones de la vacuna y pueden llevarse a cabo en varios grupos de edad diferentes. En la fase 3 se amplía el número de personas y se verifica la seguridad y su eficacia (WHO, 2020d). Para el caso de la vacuna COVID-19 y por ello de una pandemia se ha activado el PHEIC lo que implica acelerar su desarrollo, aprobación y uso masivo (AVAC, 2020). 


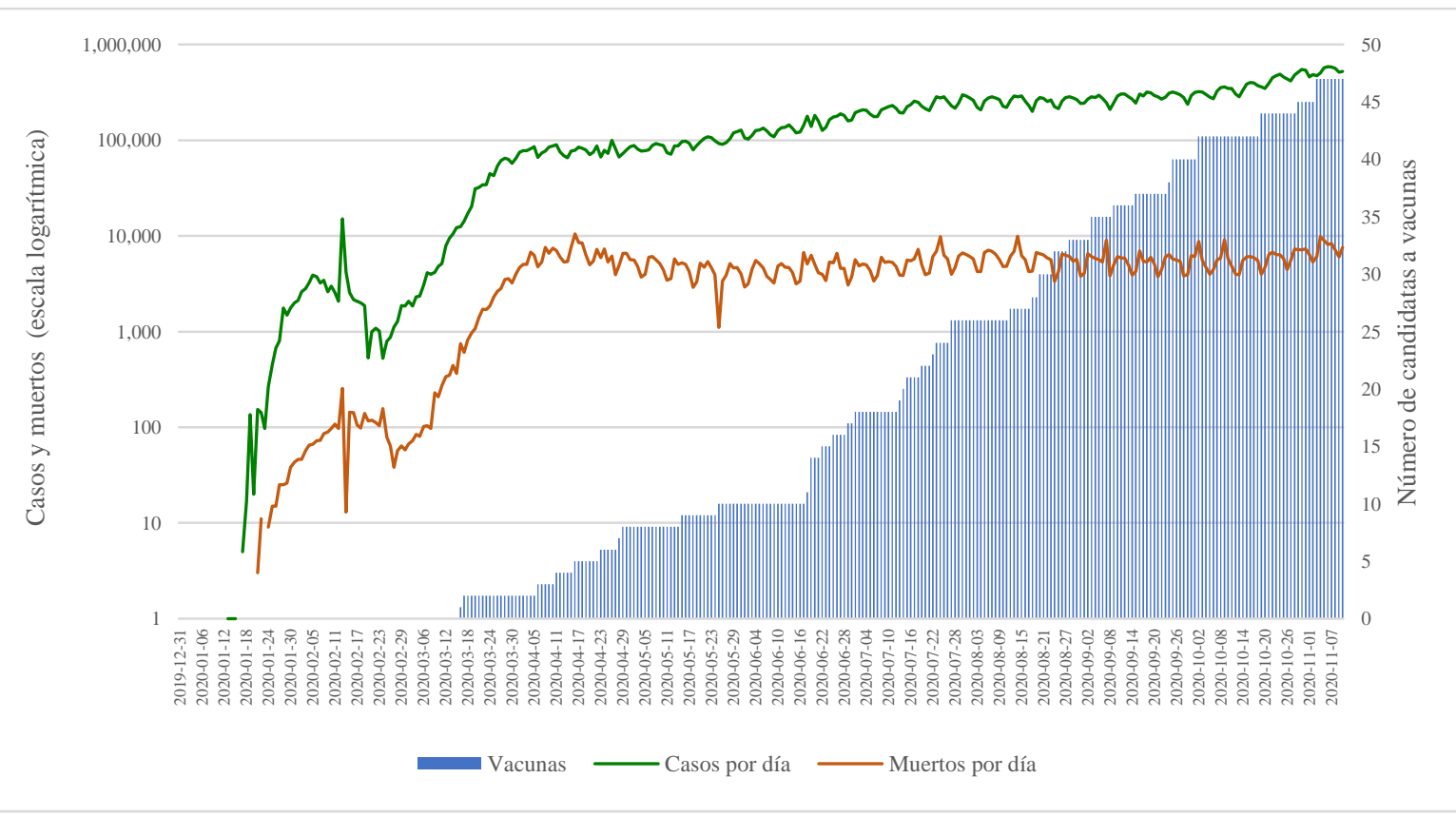

Figura 1. La pandemia COVID-19 en el mundo. Casos de contagios, muertes y candidatas a vacunas en la etapa de estudios clínicos, al 12 de noviembre de 2020 (número y escala logarítmica)

Fuente: elaboración propia con base en CDC (2020), WHO (2020a)

\section{Las candidatas a la vacuna COVID-19 en la etapa de estudios clínicos}

El desarrollo de la vacuna contra el SARS-CoV-2 inició en enero 2020 al secuenciarse el genoma del virus. Los estudios clínicos de fase 1 comenzaron en marzo y los primeros ensayos de fase 3 en julio del mismo año. El proceso para elaborar la vacuna ha sido muy rápido comparado con procesos anteriores. Tan sólo 3.1 meses después se registraba el primer estudio en humanos en un ensayo clínico que se ha logrado en un tiempo récord si se compara con otros avances para atender pandemias previas como las causadas por un virus del mismo tipo (coronavirus del SARS) o la influenza A, en las que se ha reducido en casi siete veces el tiempo para iniciar los ensayos clínicos (Callaway 2020; WHO 2020b; WHO 2020c). Al 15 de octubre de 2020 había registradas 198 candidatas a vacunas de las cuales el 27\% están en la etapa de estudios clínicos y el restante $73 \%$ se encuentran en la etapa inicial de estudios preclínicos. Nuestro ámbito muestral abarca las candidatas a vacunas en la etapa de ensayos clínicos (fases 1, 1 y 2, 2 y 3) que representan ese 27\% y está integrado por 42 candidatas a vacunas. De esa población, el $43 \%$ está en la fase 1, el 26\%, en la fase 1 y 2, el 10\% en la fase 2 y el $21 \%$ restante en la fase 3 .

\section{Características generales de las candidatas a vacuna COVID-19}

\section{La dinámica por regiones y países de origen de la vacuna}

Por regiones, los países de Asia, Europa y EUA participan en el 98\% y 2\% restante en América Latina. Sólo 19 países están desarrollando vacunas en la etapa de estudios clínicos, lo que refleja la concentración de los esfuerzos y la mayor probabilidad de acceso a las vacunas que les sean aprobadas. Los países desarrollados (PD) mantienen el liderazgo con 22 iniciativas, seguidos de Rusia-India-China (RIC) con 15 (Figuras 2 y 3). Es de destacar la presencia de países en desarrollo (PED) (Kazajistán, Indonesia y Cuba), y la ausencia de PD que cuentan con capacidades sabidas como Israel, Suiza u Holanda, y de PED como Brasil o México. Hay empresas de Italia y Austria que fueron recientemente adquiridas por una empresa británica y otra de EUA y que están en la carrera por la vacuna. 
J. Jasso-Villazul y A. Torres-Vargas / Contaduría y Administración 65(4) Especial COVID-19, 2020, 1-19 http://dx.doi.org/10.22201/fca.24488410e.2020.3134

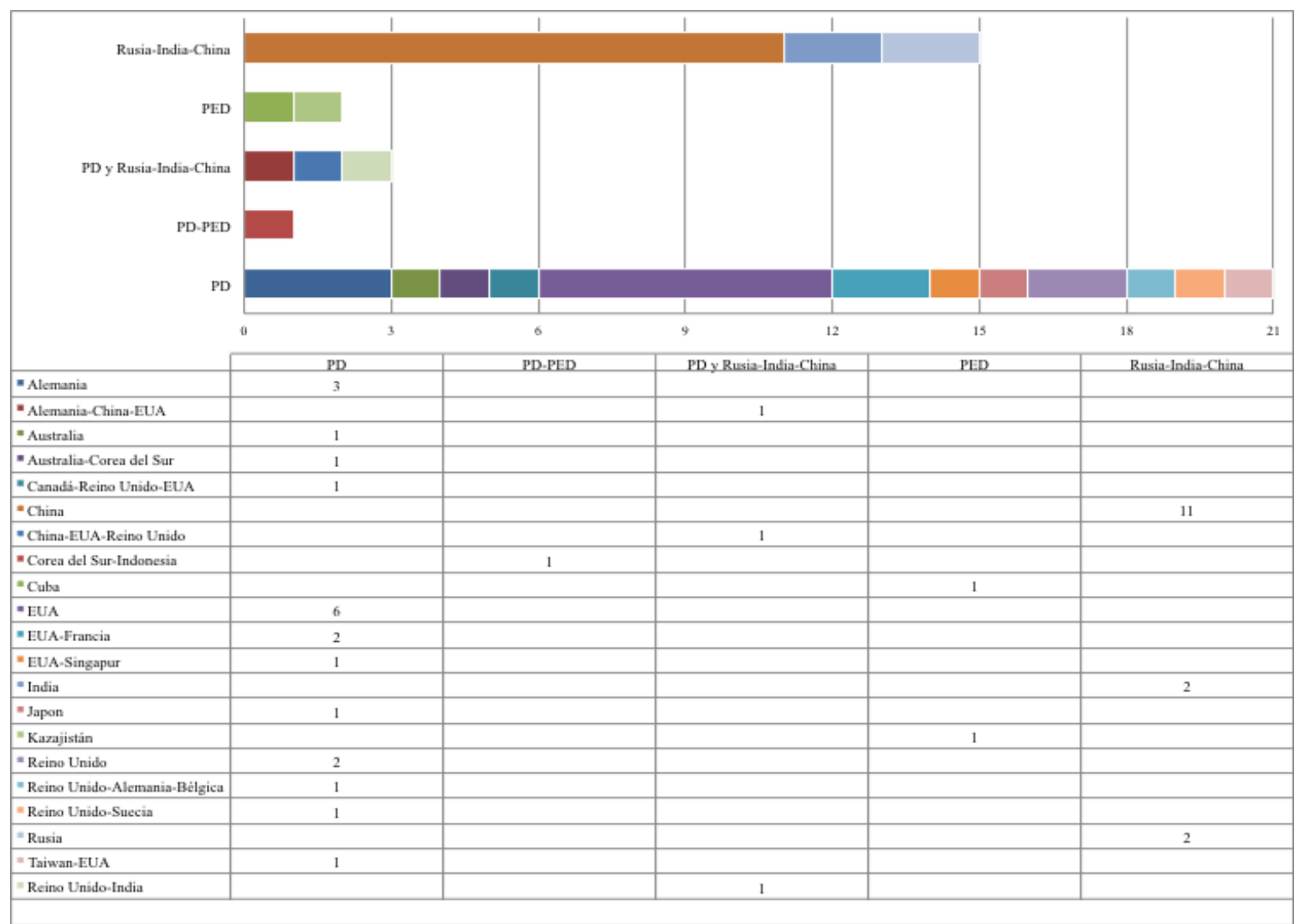

Figura 2. Proyectos de vacuna COVID-19 por grupos de países, 2020 (número al 15 de octubre de 2020, n=42) Fuente: elaboración propia a partir de WHO (2020a).

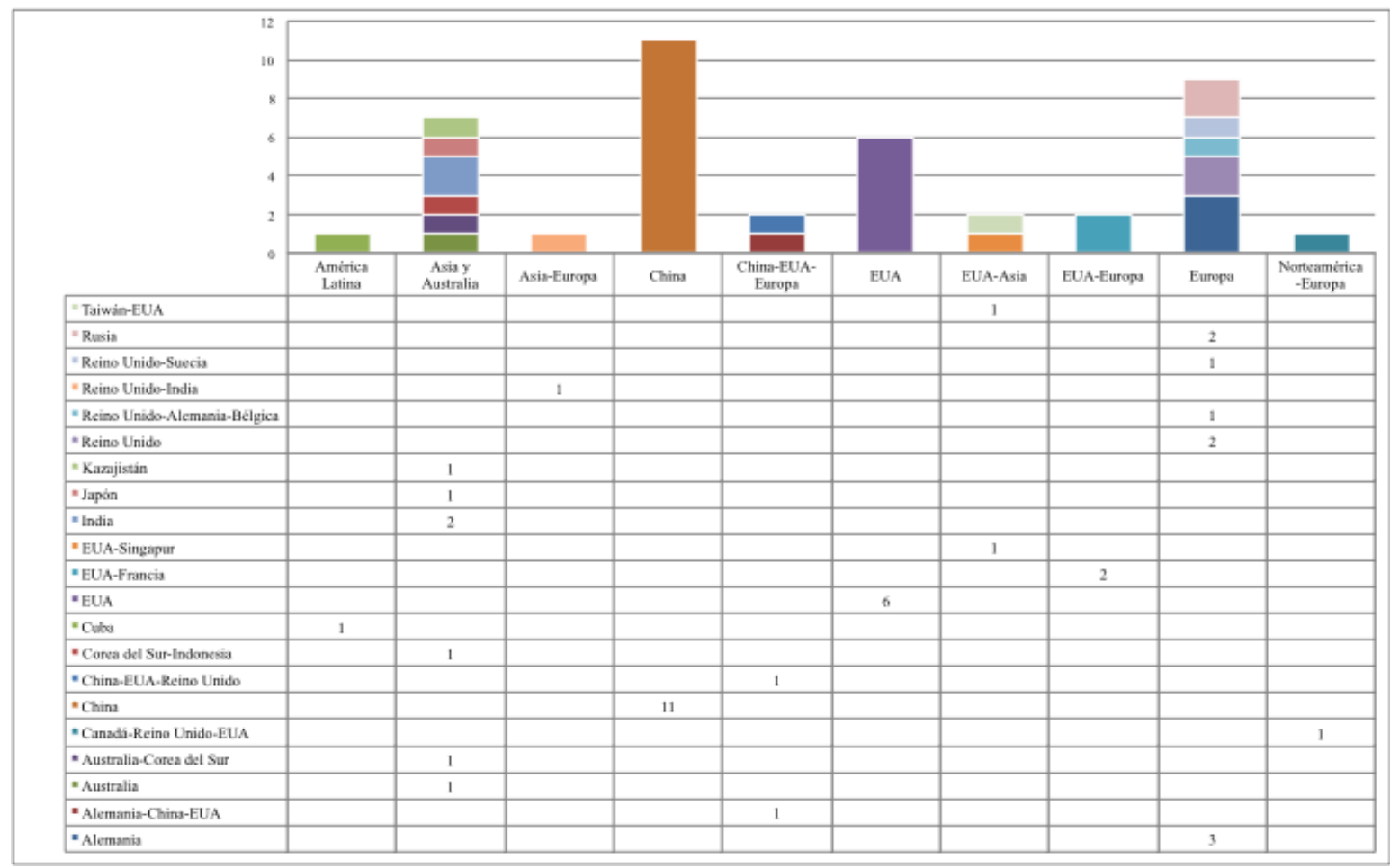

Figura 3. Proyectos de vacuna COVID-19 por regiones, 2020 (número al 15 de octubre de 2020, n=42) Fuente: elaboración propia a partir de WHO (2020a). 


\section{J. Jasso-Villazul y A. Torres-Vargas / Contaduría y Administración 65(4) Especial COVID-19, 2020, 1-19 http://dx.doi.org/10.22201/fca.24488410e.2020.3134}

A nivel de países están como líderes EUA y China con 14 y 13 iniciativas respectivamente. El Reino Unido tiene siete proyectos y Alemania cinco. Estos cuatro países representan más de la mitad de los esfuerzos por desarrollar la vacuna. En un tercer grupo está la India con tres iniciativas y con dos los países de Corea, Australia, Francia y Rusia. Finalmente, con una vacuna están Japón, Indonesia, Taiwán, Singapur, Suecia, Bélgica, Kazajistán, Canadá y Cuba (Figuras 2 y 3 ).

\section{Tipo de vacunas por plataformas tecnológicas y fases de avance}

El desarrollo de vacunas se lleva a cabo con una amplia gama de enfoques que utilizan plataformas tecnológicas convencionales y otras más innovadoras que buscan provocar una respuesta inmune. Existen distintas clasificaciones a partir de las cuales hemos agrupado las 42 candidatas a vacunas en cuatro tipos (Callaway, 2020; AVAC, 2020): a base de proteínas (36\%), genéticas (24\%), de vector viral (24\%) y de virus inactivados (16\%). Las vacunas a base de proteínas utilizan una proteína de coronavirus o un fragmento de proteína. Esta plataforma es de nueva generación, la que tiene mayor número de candidatas y la más diversificada al aparecer en empresas, CPI y universidades, aunque aún no ha llegado ninguna a la fase 3, que es la más avanzada. En esta plataforma encontramos la presencia de América Latina con la vacuna de Cuba. Las vacunas genéticas utilizan uno o más genes propios del coronavirus para provocar una respuesta inmune y se están desarrollando en la mayoría de los 19 países participantes. En este tipo de vacunas la plataforma tecnológica es de alta complejidad; al utilizar procesos sintéticos y no requerir cultivo ni fermentación, ofrecen un desarrollo y fabricación mucho más rápida. Las de vector viral utilizan otros virus para introducir en la célula el ARN del coronavirus. Estas vacunas se desarrollan en China, Asia y Australia además de Europa y EUA (Tabla 1).

Tabla 1

Los agentes desarrolladores de la vacuna COVID-19 por tipo de colaboración, 2020 (número de candidatas a vacunas al 15 de octubre del $2020, n=42$ )

\begin{tabular}{|c|c|c|c|c|c|c|}
\hline \multirow{2}{*}{ Tipo de agente-desarrollador/ Atributos de la vacuna } & \multirow{2}{*}{ Tipo de vacuna } & \multirow{2}{*}{$\begin{array}{c}\text { Tipo de } \\
\text { mecanismo }\end{array}$} & \multicolumn{4}{|c|}{ Fases } \\
\hline & & & 1 & 1 y 2 & 2 & 3 \\
\hline a. Empresas (10) & & & 4 & 2 & 2 & 2 \\
\hline Beijing Minhai Biotechnology Co., Ltd. ** & Virus inactivados & - & 1 & & & \\
\hline Sinovac $* *$ & Virus inactivados & - & & & & 1 \\
\hline Zydus Cadila Healthcare Limited $* *$ & Genética & - & & 1 & & \\
\hline Novavax & Proteínas & COVAX-OWS & & & 1 & \\
\hline Curevac & Genética & COVAX & & & 1 & \\
\hline J\&J-Janssen Pharmaceutical * & Vector viral & OWS & & & & 1 \\
\hline COVAXX-United Biomedical & Proteínas & - & 1 & & & \\
\hline Kentucky Bioprocessing (British American Tobacco Plc) & Proteínas & - & & 1 & & \\
\hline Medicago Inc. & Proteínas & - & 1 & & & \\
\hline Vaxart & Vector viral & - & 1 & & & \\
\hline b. Empresas (alianza) (6) & & & 3 & 2 & & 1 \\
\hline BioNTech/ Pfizer */ Fosun Pharma & Genética & OWS & & & & 1 \\
\hline Clover Biopharmaceuticals Inc./GSK */ Dynavax & Proteínas & COVAX & 1 & & & \\
\hline Sanofi Pasteur */ GSK * & Proteínas & OWS & & 1 & & \\
\hline Arcturus Therapeutics/ Duke & Genética & - & & 1 & & \\
\hline ReiThera-GSK*/ Leukocare/ Univercells & Vector viral & - & 1 & & & \\
\hline Vaxine Pty Ltd/Medytox & Proteínas & - & 1 & & & \\
\hline
\end{tabular}




\begin{tabular}{|c|c|c|c|c|c|c|}
\hline c. CPI/ Universidad (11) & & & 6 & 3 & 1 & 1 \\
\hline Bharat Biotech ** & Virus inactivados & - & & 1 & & \\
\hline $\begin{array}{l}\text { Chinese Academy of Medical Sciences, (Institute of Medical Biology) } \\
* *\end{array}$ & Virus inactivados & - & & 1 & & \\
\hline $\begin{array}{l}\text { Institute of Biotechnology, Academy of Military Medical Sciences, } \\
\text { PLA of China ** }\end{array}$ & Vector viral & - & 1 & & & \\
\hline Imperial College London & Genética & COVAX & 1 & & & \\
\hline University Hospital Tuebingen & Proteínas & COVAX & 1 & & & \\
\hline FBRI SRC VB Vector, Rospotrebnadzor, Koltsovo & Proteínas & - & 1 & & & \\
\hline Gamaleya Research Institute & Vector viral & - & & & & 1 \\
\hline Instituto Finlay de Vacunas & Proteínas & - & 1 & & & \\
\hline LudwigMaximilians University of Munich & Vector viral & - & & & 1 & \\
\hline Research Institute for Biological Safety Problems, Rep. of Kazakhstan & Virus inactivados & - & & 1 & & \\
\hline West China Hospital of Sichuan University & Proteínas & - & 1 & & & \\
\hline d. Empresa con CPI/ Universidad (15) & & & 5 & 4 & 1 & 5 \\
\hline Medigen Vaccine Biologics Corporation/ NIAID/ Dynavax ** & Proteínas & - & 1 & & & \\
\hline SpyBiotech/Serum Institute of India $* *$ & Proteínas & - & & 1 & & \\
\hline $\begin{array}{l}\text { Walvax Biotech/People's Liberation Army (PLA) Academy of } \\
\text { Military Sciences ** }\end{array}$ & Genética & - & 1 & & & \\
\hline AstraZeneca* / University of Oxford & Vector viral & COVAX-OWS & & & & 1 \\
\hline Inovio Pharmaceuticals/ International Vaccine Institute & Genética & COVAX-OWS & & 1 & & \\
\hline $\begin{array}{l}\text { Merck Sharp \& Dohme*-Themis / Institute Pasteur/Univ. Pittsburg } \\
\text { CVR }\end{array}$ & Vector viral & COVAX-OWS & 1 & & & \\
\hline Moderna Therapeutics* / NIAID & Genética & COVAX-OWS & & & & 1 \\
\hline CanSino Biological Inc./ Beijing Institute of Biotechnology & Vector viral & COVAX & & & & 1 \\
\hline University of Queensland/ CSL-Seqirus & Proteínas & COVAX & 1 & & & \\
\hline $\begin{array}{l}\text { Anhui Zhifei Longcom Biopharmaceutical/ Institute of Microbiology, } \\
\text { Chinese Academy of Sciences }\end{array}$ & Proteínas & - & & & 1 & \\
\hline Beijing Wantai Biological Pharmacy/ Xiamen University & Vector viral & - & 1 & & & \\
\hline Genexine Consortium & Genética & - & & 1 & & \\
\hline Osaka University/ AnGes/ Takara Bio & Genética & - & & 1 & & \\
\hline Sinopharm/ Beijing Institute of Biological Products & Virus inactivados & - & & & & 1 \\
\hline Sinopharm/ Wuhan Institute of Biological Products & Virus inactivados & - & & & & 1 \\
\hline Total general (42) & & & 18 & 11 & 4 & 9 \\
\hline
\end{tabular}

Notas: * empresas líderes mundiales (Big Pharma)

** miembros de la "Red de Fabricantes de Vacunas de los Países en Desarrollo" (Developing Countries Vaccine Manufactures Network, DCVMN).

Fuente: elaboración propia a partir de WHO (2020a), Thanh et al (2020a), Pagliusi et al (2020) y AVAC (2020)

Finalmente, las de virus inactivados o atenuados utilizan una versión debilitada o inactivada del coronavirus; esta tecnología predomina en Asia y Australia y es de las más frecuentes en las empresas chinas. Se trata de la tecnología más convencional y está entre las más seguras y utilizadas hasta ahora. En la fase 3, que es la más avanzada, se ubica el $21 \%$ de las vacunas, de las cuales el 14\% se están desarrollando con tecnologías de mayor complejidad (vector viral y genéticas) y el restante $7 \%$ con tecnologías más convencional, donde se tiene más experiencia y seguridad del proceso (virus inactivados) (Tabla 1$)$. 


\section{J. Jasso-Villazul y A. Torres-Vargas / Contaduría y Administración 65(4) Especial COVID-19, 2020, 1-19 http://dx.doi.org/10.22201/fca.24488410e.2020.3134}

\section{Naturaleza y mecanismos de colaboración científica y de financiamiento}

Hay un esfuerzo colaborativo entre agentes ya sea en el mismo país o bien a nivel internacional. La colaboración incluye la alianza entre empresas (seis casos, tres con financiamiento COVAX y OWS) y la vinculación CPI-universidad con empresas (15 casos, seis con financiamiento COVAX y OWS). En contraparte los agentes que no colaboran incluyen las empresas (10 casos, tres con financiamiento COVAX y OWS) y los CPI-universidades (11 casos, dos con COVAX). Hay una importante colaboración entre los países liderados por PD con 21 iniciativas y tres más con los RIC y una con un PED, que representan el $60 \%$ de las candidatas a vacunas. De estos 25 proyectos, 11 son de colaboración internacional de la iniciativa COVAX y el programa OWS, dos de colaboración CPI-universidad con empresa (EUA y Japón) y tres de alianzas entre empresas y sólo dos de empresas independientes (EUA, Canadá y Alemania). Esta composición manifiesta la mayor diversificación colaborativa respecto a los otros tipos de países y que les da ventaja para acceder al conocimiento científico, compartir riegos y apalancarse financieramente. En un segundo grupo están los países RIC con 18 candidatas a vacuna, de las cuales tres son con PD. El $37 \%$ es de CPI y universidades, 10\% de empresas y el restante 53\% es en colaboración. Sólo el 16\% es con financiamiento COVAX u OWS. La menor colaboración con PD refleja la cautela para vincularse, además de la relativa autosuficiencia institucional. Un tercer grupo de países lo conforman los PED con sólo dos iniciativas. Una es de un CPI público de Cuba y la otra de un CPI público de Indonesia en alianza con una empresa coreana. Esta presencia refleja las débiles capacidades institucionales y de articulación (Tabla 1 y Figuras 4 y 5).

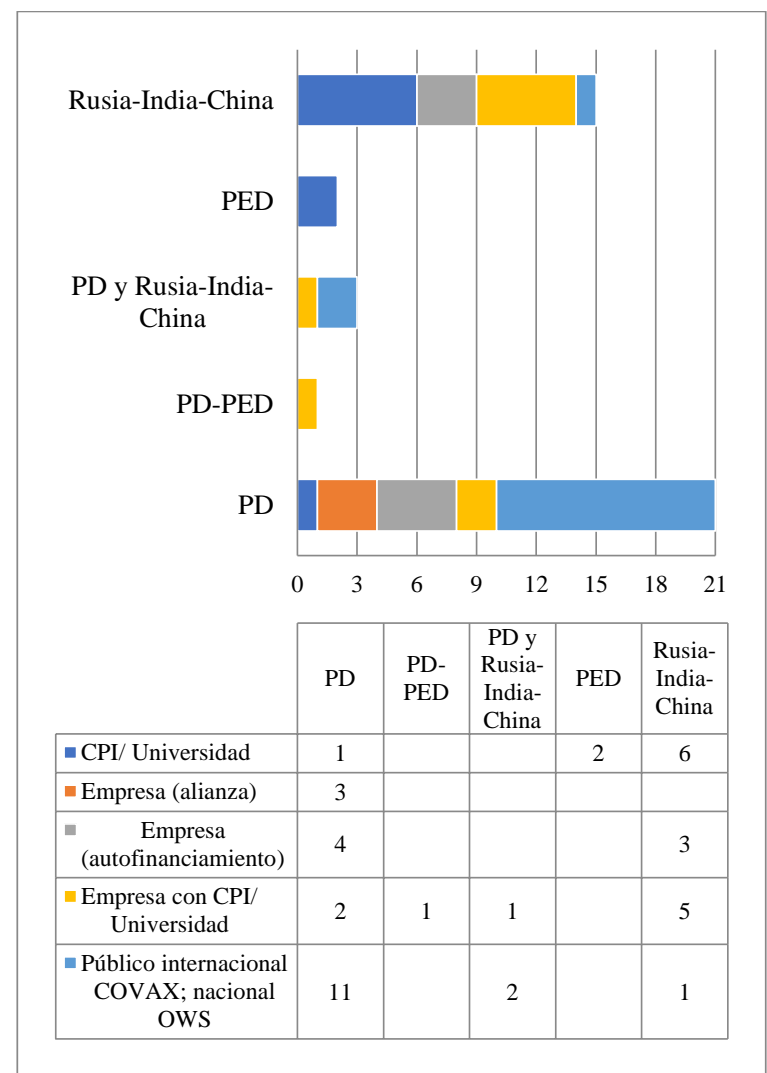

Figura 4. Candidatas a vacunas COVID-19 por tipos de países y de agentes (número al 15 de octubre de 2020, n=42)

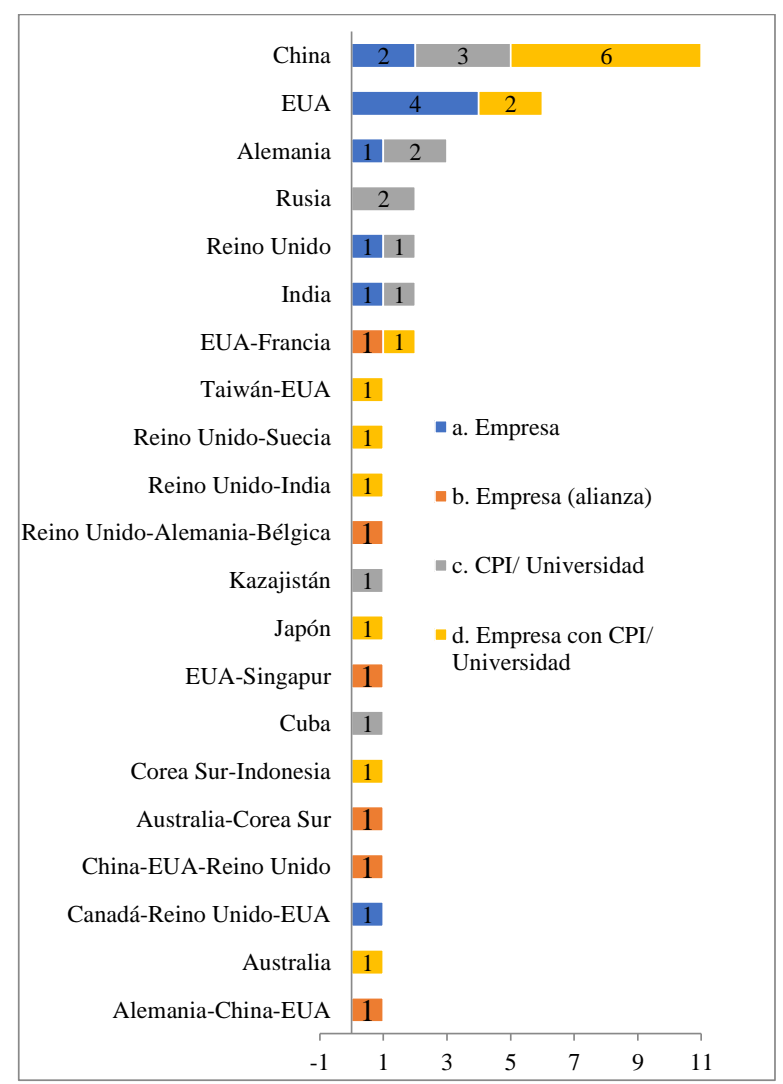

Figura 5. Candidatas a vacunas COVID-19 por países y tipo de agentes (número al 15 de octubre de 2020, $\mathrm{n}=42$ ) Thanh et al (2020a) y AVAC (2020).

Por tipo de agentes y al igual que como ocurre a nivel de países, hay una alta presencia de las empresas (74\%), ya sea en forma independiente o en colaboración, entre las que están las líderes mundiales farmacéuticas Big Pharma 


\section{J. Jasso-Villazul y A. Torres-Vargas / Contaduría y Administración 65(4) Especial COVID-19, 2020, 1-19 \\ http://dx.doi.org/10.22201/fca.24488410e.2020.3134}

como Astra Zeneca, Johnson \& Johnson, Moderna, GSK, Sanofi, Merck Sharp \& Dohme o Pfizer y las empresas biotecnológicas recien adquiridas RiuTher y Themis. En China es relevante la participación gubernamental en las empresas como son los casos de Sinopharm y Sinovac. Los CPI y universidades tienen una participación del $62 \%(26 \%$ sin colaborar y $36 \%$ colaborando con empresas). En estos CPI el papel del Estado es determinante como es el caso de países de Rusia, China, India y PED como Indonesia y Cuba. Si bien no es de extrañar que el esfuerzo por lograr vacunas esté liderado por empresas, es muy importante la participación de CPI y universidades ya sea en forma independiente o en colaboración con empresas (62\%), en redes de científicos con las propias empresas u hospitales o incluso siguiendo un camino independiente, sobre todo en los CPI de países emergentes como Cuba (Instituto Finlay de Vacunas) e Indonesia (Genexine Consortium) y el Serum Institute of India. El financiamiento más relevante (86\%) es de la iniciativa multilateral COVAX y del programa OWS que provienen principalmente de los países de Europa y EUA. Las iniciativas en colaboración son mayores en los países de Asia que participan en el 100\% de las iniciativas de universidades con CPI y universidades y el 66\% de las alianzas entre empresas (Tabla 1 y Figura 5).

\section{Las rutas y lógicas para desarrollar y distribuir la vacuna COVID-19}

A partir de los conceptos, datos e información recopilada y partiendo del fenómeno, sustentamos con base en la TF (Walsh et al, 2015) nuestro argumento relacionado con la dinámica del desarrollo de vacunas identificando diversos patrones de colaboración.

\section{La pandemia y la complejidad para desarrollar rápidamente una vacuna efectiva}

En el desarrollo y producción de la vacuna COVID-19 se está construyendo una nueva lógica más acelerada que la lógica tradicional. En la lógica tradicional la creación de una nueva vacuna comúnmente lleva de 12 a 20 años desde su invención hasta su aplicación y uso, predominan los incentivos del mercado y es liderada por las empresas Big Pharma. El proceso tradicional inicia con una fase de descubrimiento prolongada en la que se diseñan las vacunas y se llevan a cabo experimentos preclínicos exploratorios y estudios de toxicología más formales. Durante este proceso, se presenta una solicitud de "Nuevo Fármaco en Investigación" (NFI) seguida de ensayos de fases 1, 2 y 3. Una vez que los resultados de los ensayos de fase 3 cumplen los criterios de valoración se somete una solicitud de "Licencia de Biológicos" (LB) a las agencias reguladoras que finalmente autorizan la vacuna y se inician las siguientes etapas de producción y distribución y venta a gran escala (Figura 6).

En el nuevo proceso se intenta lograr lo antes posible una vacuna segura y efectiva. La OMS propone un mapa de ruta en tres fases. En la primera, se busca que la investigación y el financiamiento sean coordinados a nivel global con el uso de protocolos y herramientas de investigación robustas, y el intercambio rápido de datos y muestras. En la segunda fase, que haya un rápido acceso a intervenciones experimentales promisorios, a Ensayos Controlados Aleatorios (RCTs por sus siglas en inglés) y al uso de protocolos genéricos/ centrales para la acumulación de evidencia robusta. La fase 3 se refiere al escalamiento tecnológico y de costos efectivos, la consideración de innovaciones con potencial real de escalamiento y la evaluación económica independiente de los mercados y accesos (WHO, 2020b). Esta ruta abarca tres acciones. En el ámbito científico se han compartido los resultados de las pruebas aplicadas en las etapas preclínica y clínica. En el ámbito de la regulación se han activado mecanismos de flexibilización para permitir la combinación de fases al saltarse la fase del descubrimiento, aprovechando el conocimiento adquirido con la vacuna SARS-CoV-1 y MERS-CoV y adoptar los procesos existentes e iniciar los ensayos de fase 1/2. Los ensayos de fase 3 se iniciaron después de un análisis intermedio de los resultados de fase 1/2 con varias etapas de ensayos clínicos en paralelo. En el ámbito de 


\section{J. Jasso-Villazul y A. Torres-Vargas / Contaduría y Administración 65(4) Especial COVID-19, 2020, 1-19 http://dx.doi.org/10.22201/fca.24488410e.2020.3134}

manufactura y acceso por medio de esquemas de fabricación temprana en el que las entidades públicas y privadas financian la producción de grandes cantidades de las vacunas candidatas más prometedoras (AVAC, 2020) (Figura 6).

Mientras tanto, los productores de vacunas comenzaron la producción de "Buenas Prácticas de Producción" a gran escala en riesgo. La vía o mecanismo de concesión de licencias aún no está clara, aunque la empresa Moderna ha anunciado otorgar licencias de las patentes relacionadas con su vacuna COVID-19 mientras continúe la pandemia (Loftus, 2020). La propuesta refleja una mayor colaboración público-privado en múltiples ámbitos: en la inversión interinstituciones y de empresas; en la investigación científica; en acuerdos de fabricación regional; en el intercambio de conocimientos y de datos y en la activación de grupos formales e informales entre científicos e incluso de la presencia de CPI públicos de PED como agentes desarrolladores. Además, las agencias de regulación como la FDA han promovido una flexibilidad y rapidez sin precedentes para los laboratorios y fabricantes, para desarrollar y ofrecer pruebas del COVID19, para el desarrollo y disponibilidad de productos médicos y equipo para el uso de los pacientes, médicos y sistemas de salud. La generación de soluciones a problemas emergentes como el que se enfrenta con el COVID-19 no se fundamenta solo en el conocimiento científico, aunque este es crucial, sino en la articulación de los recursos y capacidades científicas, tecnológicos, financieros e institucionales (Figura 6).

\section{La ruta tradicional: la aceleración del mercado}

Estudios preclínicos

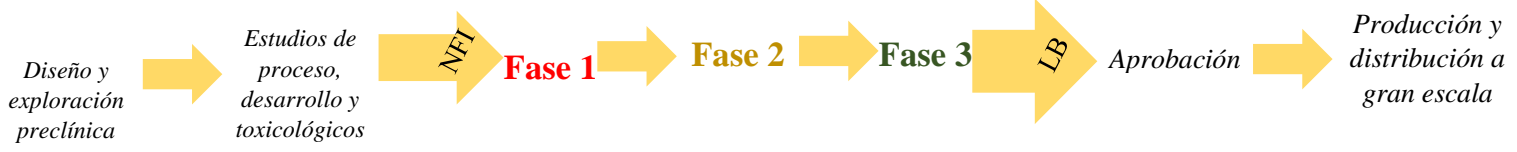

Revisión regulatoria de cada país: CDC, FDA y otras

2-4 años

1-2 años
2 años

2 años
2-3 años

1-2 años

15 años

\section{La ruta de la vacuna COVID-19: la aceleración concertada global público-privada}

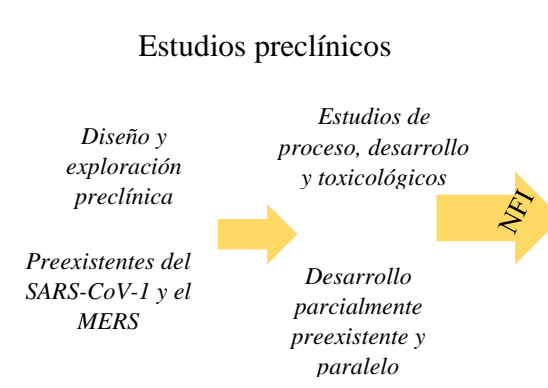

paralelo
Estudios clínicos: mayor colaboración científica empresas con CPI y universidades

Fase 3

Fases 1 y 2 (fases clínicas superpuestas)

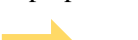

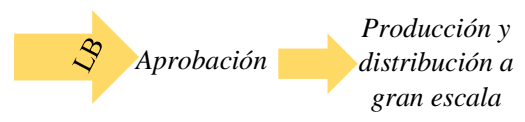

Producción en riesgo

Revisión regulatoria de cada país apoyados por la OMS: CDC, FDA y otras Financiamiento público-privado: COVAX, OWS y otros

Meses Meses Meses

De 10 a 18 meses

Figura 6. Las rutas para desarrollar vacunas tradicionales y la de COVID-19 Fuente: Elaboración propia a partir de Krammer (2020). 


\section{J. Jasso-Villazul y A. Torres-Vargas / Contaduría y Administración 65(4) Especial COVID-19, 2020, 1-19 http://dx.doi.org/10.22201/fca.24488410e.2020.3134}

\section{Las iniciativas internacionales COVAX y el programa Operation Warp Speed (OWS)}

El desafío del COVID-19 no tiene precedentes, y solo puede afrontarse con la cooperación entre CPI y universidades, empresas desarrolladoras y fabricantes, gobiernos y asociados multilaterales.

\section{La iniciativa COVAX}

La iniciativa COVAX fue creada en abril de 2020 con la finalidad de impulsar el desarrollo, producción y acceso justo y equitativo de la vacuna para la COVID-19, enmarcado en la estrategia de la OMS denominada Acelerador de Vacunas COVID-19 (ACT) (COVAX, 2020a). COVAX es codirigido por la Coalición para las Innovaciones de Preparación para Epidemias (CEPI, Coalition for Epidemic Preparedness Innovations) que es una asociación innovadora entre organizaciones públicas, privadas, filantrópicas y civiles, lanzada en Davos en 2017, para desarrollar vacunas para detener futuras epidemias, la GAVI (Alianza Mundial para Vacunas e Inmunización), que es una asociación públicoprivada creada en el año 2000, que ayuda a vacunar a niños del mundo contra algunas de las enfermedades más mortales y la OMS creada en 1948 como una institución de la ONU. El objetivo de COVAX es desarrollar al menos tres vacunas seguras y eficaces que se estima costarían \$2,100 millones de dólares (CEPI, 2020). La iniciativa garantiza el acceso, mutualizando los riesgos asociados, y mediante aportaciones por adelantado como una garantía de una cuota definida de los países miembros. Esto incluye el compromiso de "Compra Anticipada de Mercado" (AMC), donde los donantes del sector público y filantrópicos negocian un precio y planean la compra y distribución de vacunas antes de que se complete el proceso de prueba de vacunas (COVAX, 2020a). La iniciativa pretende producir dos mil millones de dosis de vacunas y distribuirlas en los 172 países miembros (WHO, 2020c). A septiembre del 2020 se habían asignado \$1,255 millones de dólares (COVAX, 2020b). Esta iniciativa registra nueve proyectos de vacunas de los cuales dos, Astra Zeneca-Universidad de Oxford y Novavax, concentran el $90.4 \%$ del financiamiento asignado. La iniciativa tiene un alcance global y una importante colaboración público-privada (Figura 7).

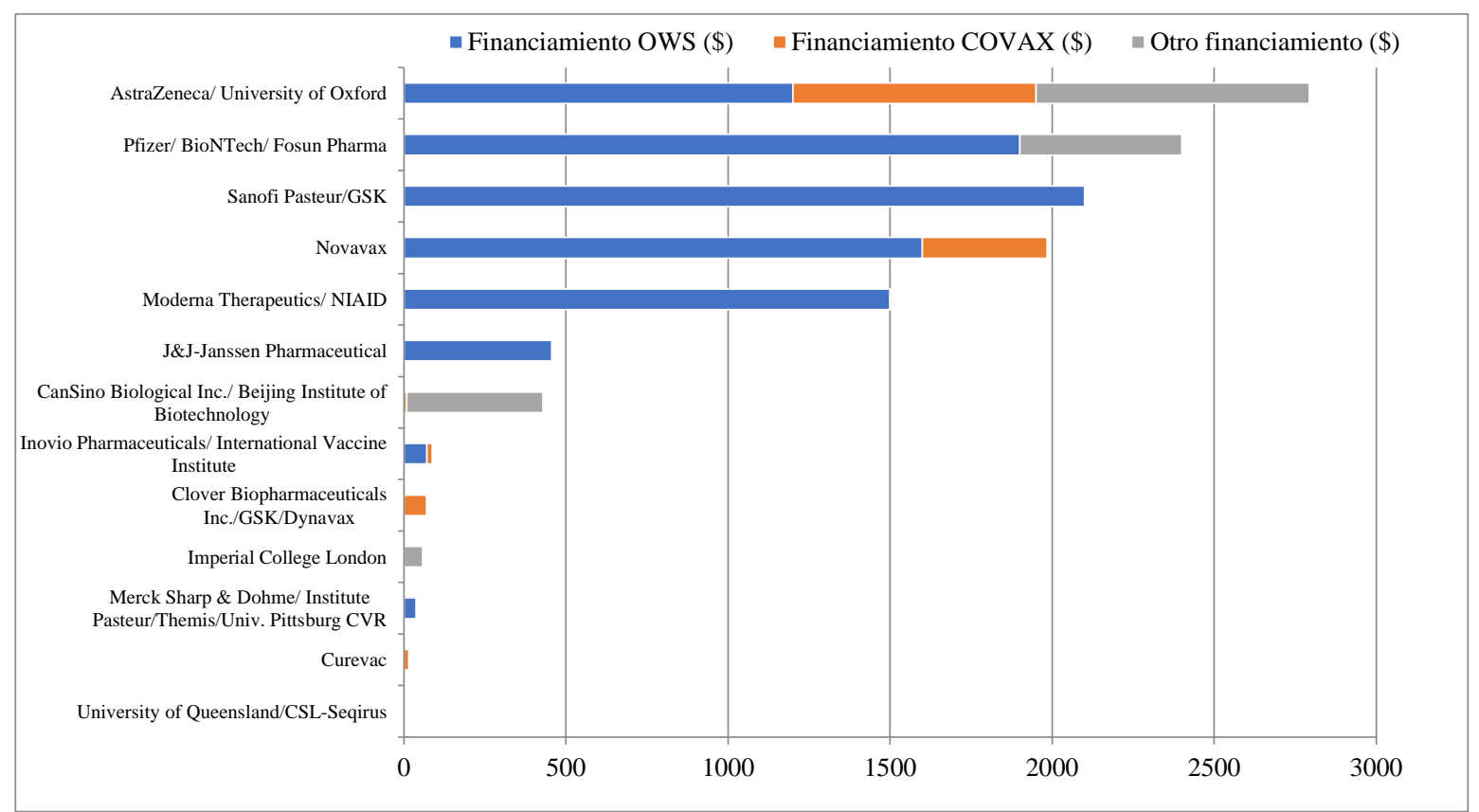

Figura 7. Empresas con financiamiento internacional COVAX, del programa OWS y de las empresas, al 17 de septiembre de 2020 (millones de dólares)

Fuente: elaboración propia con datos de CEPI (2020), COVAX (2020b), AVAC (2020), Thanh et al (2020a) e informes de las empresas. 


\section{El programa Operation Warp Speed}

Este programa proviene del gobierno de EUA a través de la asociación del Departamento de Salud y Servicios Humanos (HHS, siglas en inglés), el Departamento de Defensa y el sector privado, dado a conocer el 15 de mayo 2020 (Slaoui y Hepburn, 2020). El objetivo es controlar rápidamente la pandemia del COVID-19, mediante el desarrollo avanzado, la manufactura y la distribución de vacunas, y de diagnósticos. El programa contempla producir y administrar 300 millones de dosis para enero 2021. Esta iniciativa se basa en la experiencia lidereada por el Instituto Nacional de Salud de EUA (NIH, siglas en inglés) para combatir al virus del Zika. En este esquema, las empresas ejecutarán los procesos clínicos y de desarrollo y manufactura, mientras que el programa OWS busca apalancar la capacidad del gobierno de EUA para asegurar que no haya obstáculos técnicos, logísticos o cargas financieras que limiten el desarrollo y despliegue de las vacunas (Reina et al, 2014). Los candidatos deben de tener el potencial de entrar en la fase 3 entre julio y noviembre de 2020 y estar en plataformas tecnológicas que permitan una rápida y efectiva manufactura de la vacuna, demostrar el escalamiento industrial del proceso, y la fiabilidad de que podrán producirse más de 100 millones de dosis a mediados de 2021. Este programa es el que cuenta con mayores recursos ( $\$ 8,865$ millones de dólares), lo que es cinco veces mayor que el de la iniciativa COVAX (COVAX, 2020a y b).

En este programa están ocho proyectos de vacunas en el que participan sobre todo empresas norteamericanas como Novavax, J\&J, GSK, Pfizer, Moderna, Inovio y Merck ya sea en forma independiente o en colaboración con universidades o CPI también norteamericanos, como el National Institute of Allergy and Infectious Diseases, el International Vaccine Institute y la Universidad de Pittsburg. El único proyecto no norteamericano, es la vacuna británica de Astra Zeneca con la Universidad de Oxford. En este grupo están las empresas Big Pharma líderes mundiales desarrolladoras de vacunas que concentran el $80 \%$ del mercado mundial de vacunas (Tabla 1 y Figura 7). Este programa se enmarca en la lógica señalada por Jacobs y Mazzucato (2016), a partir de la cual asume funciones emprendedoras en la actividad productiva y sobre todo cuando hay un alto riesgo o incertidumbre, como lo es la emergencia sanitaria y que se combinan con los tiempos electorales del país financiador. Esta iniciativa tiene una orientación "nacionalista" ya que está destinada sobre todo para la población de EUA.

Otras iniciativas de empresas y de países emergentes

Finalmente están otras iniciativas que provienen de países emergentes y diversos agentes como por ejemplo, de empresas, fundaciones, CPI, universidades, u otros apoyos públicos en el que hemos identificado que han asignado un monto de \$1,826 millones de dólares (Figura 7). En el caso de los países emergentes, hay nueve proyectos de vacunas en los que participan trece miembros de la "Red de Fabricantes de Vacunas de los Países en Desarrollo" (Developing Countries Vaccine Manufactures Network, DCVMN), creada en el año 2000. Esta alianza representa a los fabricantes de vacunas que participan en la investigación, el desarrollo, la fabricación y el suministro de vacunas para uso local e internacional, con el objetivo de proteger a todas las personas contra enfermedades infecciosas conocidas y emergentes. Los miembros de esta red destacan por poseer capacidades comprobadas de fabricación, formulación, llenado, envasado y distribución (Pagliusi et al, 2020) y están familiarizados con las regulaciones y los mecanismos internacionales de suministro, incluidas las normas internacionales, los requisitos de envasado, el etiquetado y las vías reguladoras para distribuir vacunas de forma segura a través de las fronteras.

\section{La colaboración y competencia en el desarrollo y acceso de la vacuna COVID-19}

Los patrones de colaboración y competencia van desde la colaboración público-privada hasta aquellos que descansan predominantemente sobre los mecanismos del mercado. 


\section{La creciente colaboración público-privado}

La producción de la vacuna COVID-19 ha marcado el inicio de una mayor coordinación y colaboración entre gobiernos, científicos, tecnólogos, empresas y asociados multilaterales en el financiamiento y la investigación que van más allá de la lógica del mercado y que refleja un esfuerzo global para controlar la pandemia del SARS-CoV-2. La colaboración internacional es debida a las siguientes razones: explotar capacidades complementarias, incrementar su visibilidad internacional, compartir costos de proyectos de larga escala y alcance, intercambio de ideas y datos, y el compromiso para la realización de actividades conjuntas y para el financiamiento de los gobiernos (vía agencias, institutos, universidades y programas especiales), cuerpos cuasi-gubernamentales como el Banco Mundial y organizaciones no gubernamentales como la Fundación Bill y Melinda Gates (Wagner, 2006) que es de apenas de entre un 5 y $10 \%$ del financiamiento total (Loftus, 2020).

Los recursos para el financiamiento de las vacunas están concentrados en un pequeño grupo de PD (EUA, Reino Unido y Francia) y se está dirigiendo a las vacunas con plataformas de mayor dinamismo tecnológico. Las empresas más cercanas a lograr la aprobación de su vacuna, son las que han contado con financiamiento público de COVAX o del programa OWS, muchas de ellas son las líderes a nivel mundial. Hasta ahora COVAX ha asegurado varias decenas de millones de dosis con las empresas desarrolladoras a bajos precios. Estos acuerdos evidencian por un lado una mayor colaboración interinstitucional e internacional y de mayor inclusión a nivel global para acceder a la vacuna. En contraste, los PED están al margen del financiamiento supranacional lo que evidencia las diferencias institucionales y la limitada participación de otras empresas y CPI sobre todo de PED o de los RIC, lo que reduce las oportunidades para ampliar las posibilidades de desarrollar un mayor número de vacunas y además de reducir las brechas estructurales en conocimiento y tecnología (Tabla 1 y Figura 7). Iniciativas como COVAX, la del programa OWS y otras están aplicando diferentes enfoques para acelerar el desarrollo de la vacuna COVID-19 no sólo mediante la colaboración en la investigación y el desarrollo, sino para la aprobación rápida de las vacunas que demuestren ser seguras y eficientes, así como para que la población mundial pueda tener acceso a la misma, independientemente de sus distintos niveles de ingreso (WHO, 2020c).

Los patrones de colaboración y competencia: desarrollo y acceso

En el mercado de vacunas las empresas desarrolladoras y productoras del sector farmacéutico siguen en principio su propia lógica en la que intentan maximizar su rentabilidad, disminuyendo el riesgo en la inversión. No es de extrañar que las empresas líderes de producción de vacunas BigPharma también estén entre las punteras para lograr la vacuna de la COVID-19 como la de cualquier otra enfermedad. Cuando la enfermedad pasa a convertirse en pandemia y se transforma en una emergencia global se activan los mecanismos institucionales multilaterales para acelerar su producción y disminuir el impacto de la pandemia, como ha ocurrido en las últimas experiencias previas de otras enfermedades como el Zika, Lassa, Chikunguya, Marburg, SFTS, Nipah, Êbola, MERS o SARS (Gouglas et al, 2018) e incluso con iniciativas globales surgidas desde el 2013 (Kieny et al, 2020). En este patrón de colaboración intervienen otros agentes reguladores como son los Estados e institucionales multilaterales que crean incentivos y mecanismos de articulación entre los agentes públicos y privados para explorar y explotar en forma colectiva las capacidades científicas y tecnológicas para crear la vacuna. En esta lógica el Estado intenta resolver una falla de mercado en las etapas iniciales del desarrollo de vacunas en los que se requieren altas inversiones en I+D que no necesariamente logran llegar al usuario o mercado, y también cubriendo fallas en el mercado en las etapas posteriores de escalamiento y manufactura e incluso de acceso al usuario final. Este patrón identificado con la inicativa COVAX se focaliza en todas las etapas para resolver la pandemia, desde el desarrollo (I+D), la manufactura y el acceso masivo de la vacuna incluyendo a la población de países de altos y bajos ingresos. Esta iniciativa implica la coordinación de esfuerzos entre países, instituciones multilaterales y empresas, posibilitando el financiamiento de las empresas e instituciones privadas y públicas para desarrollar una vacuna que asume 


\section{J. Jasso-Villazul y A. Torres-Vargas / Contaduría y Administración 65(4) Especial COVID-19, 2020, 1-19 http://dx.doi.org/10.22201/fca.24488410e.2020.3134}

características de bien semi-público al difundirla a menores precios para que países de menores ingresos que no cuentan con recursos para pagarla puedan utilizarla asumiendo criterios de equidad y justicia (Tabla 2).

Por otro lado, el patrón de colaboración "nacionalista" OWS es una iniciativa del Gobierno de EUA en la que se apoyarán todas las etapas para crear la vacuna como es la I+D a la manufactura. En este esquema puede deducirse que el acceso será principalmente para los ciudadanos de EUA. En esta iniciativa predominan los fondos públicos y tendría un alcance menos global que la de COVAX. Se centra más en acelerar la producción y no se identifica alguna estrategia de acceso global equitativo. Este esquema, a diferencia del COVAX no propone mecanismos más allá de los de mercado. En los otros patrones como los de las "empresas con CPI y universidades", y el de las "empresas", prevalece una lógica de mercado o de acuerdos entre países y empresas y en donde los consumidores aseguren su acceso mediante el mecanismo de precios (Tabla 2).

Tabla 2

Los patrones de desarrollo y acceso a la vacuna COVID-19

\begin{tabular}{lllll}
\hline \multicolumn{1}{c}{ Tipo de patrón } & $\begin{array}{c}\text { I+D y desarrollo de la } \\
\text { vacuna }\end{array}$ & $\begin{array}{l}\text { Escalamiento } y \\
\text { Manufactura }\end{array}$ & $\begin{array}{c}\text { Distribución y } \\
\text { acceso }\end{array}$ & Alcance \\
\hline $\begin{array}{l}\text { Colaboración público-privada } \\
\text { supranacional (iniciativa } \\
\text { COVAX) }\end{array}$ & $\begin{array}{l}\text { Acuerdos multilaterales } \\
\text { entre gobiernos, CPI y } \\
\text { empresas }\end{array}$ & $\begin{array}{l}\text { Iniciativas entre } \\
\text { países y agencias } \\
\text { multilaterales }\end{array}$ & $\begin{array}{l}\text { Acuerdos de } \\
\text { distribución por } \\
\text { precompra }\end{array}$ & Global \\
$\begin{array}{l}\text { Colaboración público-privada } \\
\text { nacionalista } \text { (programa OWS) }\end{array}$ & $\begin{array}{l}\text { Acuerdos de Gobiernos } \\
\text { (EUA) con agentes }\end{array}$ & $\begin{array}{l}\text { Iniciativa del país } \\
\text { que financia } \\
\text { (EUA) }\end{array}$ & $\begin{array}{l}\text { Nacional, (países } \\
\text { con acuerdo) }\end{array}$ & $\begin{array}{l}\text { Nacional (países } \\
\text { con } \\
\text { acuerdo), }\end{array}$ \\
$\begin{array}{l}\text { Colaboración empresas con } \\
\text { CPI y universidades }\end{array}$ & Acuerdos entre agentes & $\begin{array}{l}\text { Iniciativas entre } \\
\text { agentes públicos y } \\
\text { privados }\end{array}$ & $\begin{array}{l}\text { Acuerdos con } \\
\text { agentes públicos y } \\
\text { privados }\end{array}$ & Limitado \\
$\begin{array}{l}\text { Competencia entre empresas. } \\
\text { Mercado }\end{array}$ & Esfuerzo propio & Esfuerzo propio & Mercado (precios) & Limitado \\
& & & &
\end{tabular}

No se descarta que a pesar del impulso a mecanismos como el COVAX, los países de más bajos ingresos tengan dificultades para tener acceso a las vacunas. Los países de mayores ingresos ya han llegado a acuerdos para comprar más de 2.8 mil millones de dosis de vacunas, que pudieran dejar una oferta limitada en el mercado para el año 2021. Hacia finales de agosto, EUA había asegurado 800 millones de dosis de al menos seis de las vacunas en desarrollo, con opción de comprar mil millones más. Japón ha hecho arreglos bilaterales y las naciones europeas están comprando vacunas asociadas en grupos. La Comisión Europea ha firmado contratos con las empresas Oxford-Astra Zeneca, Moderna, PfizerBioNTech-Fosum Pharma, Novavax, Sanofi-GSK, Curevac y Jansen para adquirir alrededor de 2 mil millones de dosis. El Reino Unido ha comprado el equivalente a cinco dosis por cada uno de sus habitantes. Queda la pregunta acerca de la capacidad de manufacturar las dosis que el mundo requiere. Algunas tecnologías, como las genéticas, nunca han sido producidas en los volúmenes que las empresas manufactureras esperan alcanzar. Dada la magnitud de la población mundial, el portafolio de vacunas apunta a reducir el riesgo que implica la novedad del reto. La colaboración y coordinación global debiera reforzarse como una iniciativa permanente, fortaleciendo los mecanismos para el desarrollo, producción y acceso de productos como las vacunas. 


\section{Conclusiones}

El proceso de desarrollo de la vacuna COVID-19 se enmarca dentro de un esquema que contiene elementos relacionados con las características de innovación, competencia y colaboración de la industria farmacéutica tradicional aunado a una mayor coordinación y colaboración entre gobiernos, investigadores, empresas y asociados multilaterales en la investigación y el financiamiento de la investigación que van más allá de la lógica del mercado. Las 42 candidatas a vacunas en la etapa final de estudios clínicos reflejan la pronta respuesta a la emergencia mundial. A pesar de que sólo 19 países participan en esta etapa, es evidente la mayor presencia de empresas, CPI y universidades en las que no sólo están las típicas empresas multinacionales desarrolladoras de vacunas, sino que están participando nuevos entrantes sobre todo de los RIC y PED. En conjunto, los PD y los RIC son los que participan en más iniciativas, sobre todo EUA y China, África y América Latina están prácticamente ausentes. Con el 50\% de las iniciativas es clara la necesidad de la colaboración entre los agentes privados (empresas) y públicos (CPI y universidades y gobiernos e instituciones regulatorias nacionales e internacionales), así como de la puesta en marcha de mecanismos de cooperación en toda la trayectoria de desarrollo, manufactura y distribución de la vacuna. Aunque ya existían experiencias de colaboración entre esta diversidad de agentes en varios niveles de amplitud y profundidad, la velocidad de respuesta ante la pandemia ha acentuado estos esquemas en los que se combinan incentivos y requerimientos que impulsan la colaboración y la aceleración en la regulación. El 26\% de las candidatas a vacuna se desarrollan en fases simultáneas 1 y 2.

La velocidad con que se ha impulsado el desarrollo de vacunas contra la COVID-19 está siendo posible por el conocimiento acumulado, por las capacidades institucionales y de articulación entre empresas y CPI-universidades y agencias reguladoras de los países que han conformado nuevos esquemas de colaboración público-privado. La colaboración ha sido de mayor intensidad a la de epidemias o pandemias previas ya que en la de COVID-19 ha habido una mayor flexibilidad regulatoria y se han generado nuevos mecanismos de coordinación y financiamiento público y privado para promover la aceleración internacional. Esta aceleración de la vacuna COVID-19 refleja cuatro patrones en los que cooperan o compiten las empresas y CPI y universidades a partir de los cuales anticipamos que se cuente con la capacidad de fabricar, llenar, terminar y suministrar rápidamente las vacunas COVID-19 necesarias. En el primero de carácter multilateral es impulsado por organismos como la OMS y es el que parece ser el de mayor cobertura y acceso entre países. El segundo es impulsado por el gobierno de EUA y el que cuenta con mayores recursos públicos de alcance limitado, dado que la asignación preferente será a la población de EUA. El tercer patrón abarca la colaboracion CPI y universidades sobre todo públicas con apoyo de los gobiernos nacionales con empresas en los que el desarrollo, manufactura y acceso estará definido por los acuerdos de la vinculación entre ambos agentes. Finalmente, el patrón de competencia entre empresas sigue un comportamiento de mercado guiado sobre todo por criterios de precios.

Las vacunas para las enfermedades infecciosas epidémicas necesitan la atención y los esfuerzos de inversión del mundo, ya que son costosas y para un solo agente o empresa privada no sería rentable. De ahí la importancia de la vinculación CPI y universidades con las empresas para acelerar las etapas iniciales de la vacuna, más asociadas con el conocimiento de base en la secuenciación del genoma y etapa preclínica. En este proceso las capacidades de investigación básica generadas en los CPI y universidades se amalgaman con las generadas en las empresas. La colaboración entre agentes y países es necesaria para responder de manera eficaz, no solo a ésta, sino a posibles epidemias futuras, acelerando el desarrollo y acceso a las vacunas y a otras soluciones médicas y evitar crisis humanitarias.

El desarrollo de la vacuna COVID-19 ha retomado experiencias previas de colaboración mundial que han impulsado la flexibilización de los requisitos para ir validando las fases subsecuentes hasta la fabricación de la vacuna, disminuyendo la cantidad de datos o pruebas, sin que se socave la seguridad de la vacuna. El proceso parece reflejar un acuerdo de mayor participación colaborativa y de mayor inclusión a nivel global. Sin embargo, este esquema, si se queda en una repuesta puramente inmediatista y coyuntural que no contribuirá a reducir las brechas estructurales existentes en el 
mundo en cuanto al espacio del conocimiento y tecnología, y por ende a reducir la exclusión de los países menos desarrollados. Los brotes en los últimos años indican que aparentemente la humanidad se verá amenazada repetidamente y con mayor frecuencia que antes por este tipo de pandemias, por lo que es necesario estar preparados en dar una respuesta rápida a las emergencias de gran impacto social. Estas experiencias de colaboración debieran de fortalecerse y considerar las capacidades de cada agente combinando los incentivos para lograr un resultado de beneficio colectivo que incluso pudiera retomarse para abordar otros dilemas como el medioambiente y desarrollo de energías alternativas y el desciframiento del código genético humano. Evidentemente los beneficios alcanzados debieran regir criterios de asignación económicos, políticos y sociales compartidos globalmente. La colaboración y la coordinación público-privada, entonces, podrían tener una mayor participación junto con los mecanimos de competencia para el desarrollo de los tratamientos y vacunas del futuro y que esta experiencia sea la base para prever y resolver problemas globales como los relacionados con el cambio climático, la migración, el narcotráfico o nuevas pandemias.

\section{Referencias}

AVAC (Global Advocacy for HIV Prevention) (2020). Advocates' Guide: The risks and benefits of expedited COVID-19 vaccine research, Agosto.

Callaway, E. (2020). The race for coronavirus vaccines, Nature, 580, 576-577. https://doi.org/10.1038/d41586-02001221-y

CDC (European Centre for Disease Prevention and Control), European Union. Disponible en: https://www.ecdc.europa.eu/en/covid-19-pandemic (Consultado: 17 de septiembre de 2020).

CEPI (Coalition for Epidemic Preparedness Innovations) (2020). COVAX: la respuesta de CEPI a COVID-19. Disponible en: https://cepi.net/covax/ (Consultado: 15 de septiembre de 2020).

COVAX (2020a). The COVAX facility. Global procurement for COVID-19 Vaccines, COVAX Speed, Scale, Access, COVAX.

COVAX (2020b). COVAX, the act-accelerator vaccines pillar. Insuring accelerated vaccine development and manufacture, COVAX Speed, Scale, Access, COVAX.

Demirel, P. y Mazzucato, M. (2010). The evolution of Firm Growth Dynamics in the US Pharmaceutical Industry. Regional Studies, 44 (8), 1053-1066. https://doi.org/10.1080/00343400903241469

Etzkowitz, H., y Leydesdorff, L. (2000). The dynamics of innovation: From National Systems and "mode 2" to a Triple Helix of university-industry-government relations, Research Policy, 29 (2), 109-123. doi: 10.1016/S00487333(99)00055-4

Evaluate Pharma (2017). World Preview 2017, Outlook to 2022, $10^{\text {th }}$ edition, Junio.

Glaser, B. G., y Strauss, A. L. (1967). The discovery of grounded theory: Strategies for qualitative research. New York: Aldine. https://doi.org/10.4324/9780203793206-1

Gouglas D., Thunh T., Henderson K., et al (2018). Estimating the cost of vaccine development against epidemic infectious diseases: a cost minimisation study. Lancet Glob Health, Vol. 6. http://dx.doi.org/10.1016/S2214109X (18) 30346-2.

Hirschman, E. y Thompson, C., (1997). Why media matter: Toward a richer understanding of consumers' relationships with advertising and mass media, Journal of Advertising, 26 (1), 43-60. https://doi.org/10.1080/00913367.1997.10673517

Jacobs, M. y Mazzucato, M. (2016). Rethinking Capitalism. Economics and Policy for Sustainable and Inclusive Growth. Wiley-Blackwell Ltd. W. Sussex, RU.

Kieny, M., Rottingen J, y Farrar J. (2020). The need for global R\&D coordination for infectious diseases with epidemic potential, The Lancet, 388, 460-461. https://doi.org/10.1016/s0140-6736(16)31152-7

Loftus, P. (2020). Moderna Vows to Not Enforce Covid-19 Vaccine Patents During Pandemic, Wall Street Journal, 8 de octubre.

Krammer, F. (2020). SARS-CoV-2 vaccines in development, Nature, Accelerated Article Preview. https://doi.org/10.1038/s41586-020-2798-3

Lurie, N., Saville, M., Hatchett, R., y Halton, J. (2020). Developing Covid-19 Vaccines at Pandemic Speed, The New England Journal of Medicine, 382, 1969-1973, doi: 10.1056/NEJMp2005630

Pagliusi, S., Jarrett S., Hayman, B., Kreysa, U., Prasad, S., Reers, M., Hong, P., Wuh, K., Tao, Y., Ok, Y., Kumar, A., Evtushenko A., Jadhavm S., Meng W., Tuan D., Huang W., y Desai S. (2020). "Emerging manufacturers 
engagements in the COVID 19 vaccine research, development and supply", Vaccine, 38, 5418-5423. https://doi.org/10.1016/j.vaccine.2020.06.022

Polanyi, K. (1944). The Great Transformation: The Political and Economic Origins of Our Time. Reimpreso 2001, Beacon Press, Boston, MA.

Reina, J., López, C., Rojo, E., y Rubio, R. (2014). Características de las infecciones respiratorias agudas causadas por los coronavirus OC43, NL63 y 229E, Revista Clínica Española, $214 \quad$ (9), $499-504$. http://dx.doi.org/10.1016/j.rce.2014.05.020.

Slaoui, M. y Hepburn, M. (2020). Developing Safe and Effective Covid Vaccines - Operation Warp Speed's Strategy and Approach, The New England Journal of Medicine, 382, 1969-1973, doi: 10.1056/NEJMp2027405

Tenorio, A. (2007). Virus nuevos, virus viejos, Enferm Infecc Microbiol Clin., 25 (9), 559-60. doi 10.1157/13111180

Thanh, T., Cramer J., Chen, R., y Mayhew, S. (2020a). Evolution of the COVID-19 vaccine development landscape, Nature Reviews Drug Discovery, 19, 667-668, https://doi.org/10.1038/d41573-020-00151-8.

Thanh, T., Andreadakis Z., Kumar, A., Gómez, R., Tollesfen, S., Saville, M. y Mayhew, S. (2020b). The COVID-19 vaccine development landscape, Nature Reviews Drug Discovery, 19, 305-306. https://doi.org/10.1038/d41573020-00073-5

Walsh, I., Holton J., Bailyn L., Fernández W., Levina N., y Glaser B., (2015). What Grounded Theory Is... A Critically Reflective Conversation Among Scholars, Organizational Research Methods, 18 (4), 581-599. doi: $10.1177 / 1094428114565028$

WHO (World Health Organization) (2020a). Draft landscape of COVID-19 candidate vaccines. Disponible en: https://www.who.int/publications/m/item/draft-landscape-of-covid-19-candidate-vaccines (Consultado: el 15 octubre de 2020).

WHO (World Health Organization) (2020b). A coordinated global Research roadmap 2019 novel coronavirus, WHO, Génova, marzo.

WHO (World Health Organization) (2020c). Access to Covid-19 Tools (Act) Accelerator. A Global Collaboration to Accelerate the Development, Production and Equitable Access to New COVID-19 diagnostics, therapeutics and vaccines, April 24.

WHO (World Health Organization) (2020d). Feasibility, Potential Value and Limitations of Establishing a Closely Monitored Challenge Model of Experimental COVID-19 Infection and Illness in Healthy Young Adult Volunteers, Final Report - Draft for Public Comments, 2020.

Wagner, C. (2006). International collaboration in science and technology promises and pitfalls. En Box, L. y Engelhard, R., Science and Technology Policy for Development, Dialogues at the Interface. Antem Press, Londres, RU. 